\title{
Early rectal stenosis following stapled rectal mucosectomy for hemorrhoids
}

\author{
Sven Petersen*, Gunter Hellmich, Dietrich Schumann, Anja Schuster and \\ Klaus Ludwig
}

\author{
Address: Department of General- and Abdominal Surgery, General Hospital Dresden-Friedrichstadt, Teaching Hospital Technical University of \\ Dresden, Dresden Germany \\ Email: Sven Petersen* - petersen-sv@khdf.de; Gunter Hellmich - hellmich-gu@khdf.de; Dietrich Schumann - dietrich_schumann@web.de; \\ Anja Schuster - schuster-an@khdf.de; Klaus Ludwig - ludwig-kl@khdf.de \\ * Corresponding author
}

Published: 21 May 2004

BMC Surgery 2004, 4:6

This article is available from: http://www.biomedcentral.com/I47I-2482/4/6

(C) 2004 Petersen et al; licensee BioMed Central Ltd. This is an Open Access article: verbatim copying and redistribution of this article are permitted in all media for any purpose, provided this notice is preserved along with the article's original URL.
Received: 05 January 2004

Accepted: 21 May 2004

\begin{abstract}
Background: Within the last years, stapled rectal mucosectomy (SRM) has become a widely accepted procedure for second and third degree hemorrhoids. One of the delayed complications is a stenosis of the lower rectum. In order to evaluate the specific problem of rectal stenosis following SRM we reviewed our data with special respect to potential predictive factors or stenotic events.
\end{abstract}

Methods: A retrospective analysis of 419 consecutive patients, which underwent SRM from December 1998 to August 2003 was performed. Only patients with at least one follow-up check were evaluated, thus the analysis includes 289 patients with a mean follow-up of 281 days $( \pm 18$ days).

For statistic analysis the groups with and without stenosis were evaluated using the Chi-Square Test, using the Kaplan-Meier statistic the actuarial incidence for rectal stenosis was plotted.

Results: Rectal stenosis was observed in 9 patients (3.1\%), eight of these stenoses were detected within the first 100 days after surgery; the median time to stenosis was 95 days. Only one patient had a rectal stenosis after more than one year. 8 of the 9 patients had no obstructive symptoms, however the remaining patients complained of obstructive defecation and underwent surgery for transanal strictureplasty with electrocautery. A statistical analysis revealed that patients with stenosis had significantly more often prior treatment for hemorrhoids $(p<0.01)$. According to the SRM only severe postoperative pain was significantly associated with stenoses $(p<0.01)$. Other factors, such as gender $(p=0.11)$, surgical technique $(p=0.25)$, revision $(p=0.79)$ or histological evidence of squamous skin $(p=0.69)$ showed no significance.

Conclusion: Rectal stenosis is an uncommon event after SRM. Early stenosis will occur within the first three months after surgery. The majority of the stenoses are without clinical relevance. Only one of nine patients had to undergo surgery for a relevant stenosis. The predictive factor for stenosis in the patient-characteristics is previous interventions for hemorrhoids, severe postoperative pain might also predict rectal stenosis. 


\section{Background}

Within the last years, stapled rectal mucosectomy (SRM) has become a widely accepted procedure for second and third degree hemorrhoids. In comparison to conventional hemorrhoidectomy, the reduction of postoperative pain and the shorter hospital stay made SRM a recommended surgical procedure. Although a recently published review showed data that there is no conclusive evidence for the benefit of stapled procedure patients acceptance is high $[1,2]$. Stapled hemorrhoidectomy can be regarded as a well-established procedure with relatively low complication rates. However, these complications might be severe [3]. Stricture of the lower rectum is regarded as an uncommon complication after SRM [4]. However, when a stenosis occurs this causes prolonged treatment and eventually additional surgery.

In order to evaluate the results we reviewed our prospective data with special respect to rectal stenosis and potential predictive factor for its occurrence.

\section{Methods}

Between December 1998 and December 2002, a total of 419 patients were treated surgically for second and third grade hemorrhoids at the Department of General and Abdominal Surgery at the Dresden-Friedrichstadt Hospital. Patients were observed three months and one year after surgery. 130 patients (31\%) were lost to follow-up, including 57 patients, who's follow-up was a telephone questionnaire, and 73 patients, which were not seen at the follow-up examinations. Consequently, for this study we reviewed the data of the 289 patients who underwent stapled mucosal resection and who had at least completed the first follow-up appointment. The mean follow-up was 281 days ( \pm 18 days).

SRM was regularly performed under general anesthesia; patients were placed in lithotomy position. Single shot antibiosis was not given routinely. According to the surgeons assessment one or two pursestring sutures were carried out and the PPH $33 \mathrm{~mm}$ Ethicon Endosurgery ${ }^{\varpi}$ stapler device was used. Additional stitches for hemostasis were performed regularly at the stapled ring using monofilament resorbable sutures. Patients left the hospital as soon as they felt comfortable; no day-surgery was performed.

Patients were invited for follow-up checks after a threemonth and a one-year interval. Stenosis was defined as stricture of the lower rectum that cannot be passed by the finger.

\section{Statistical methods}

Statistical analysis was performed using the SPSS 10.0.7 software package (SPSS Inc., USA). Pearson chi-squaretest compared the incidence of variables for the groups

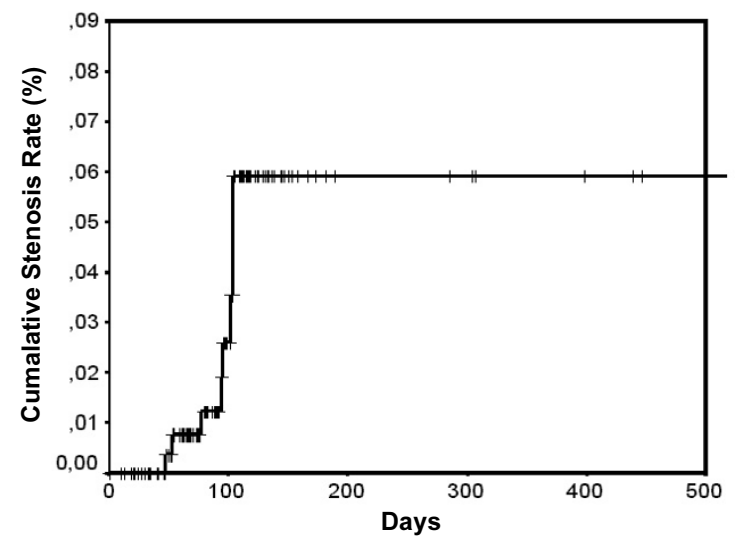

\section{Figure I}

Lower rectal stenosis after SRM: actuarial complication curve calculated and plotted by the Kaplan-Meier life-table method.

with or without stenosis. The actuarial complicationcurve was calculated and plotted according to the KaplanMeier life-table method. Variables with p-value less than 0.05 were considered to be significant.

\section{Results}

Rectal stenosis was observed in 9 patients (3.1\%), eight of these stenoses were detected within the first 100 days after surgery. The time to stenosis ranged from 47 to 1596 days, the median time to stenosis was 95 days. Only in one patient the rectal stenosis was observed after 1596 days (Figure 1). 8 of the 9 patients had no obstructive symptoms, however the patient who complained of obstructive defecation underwent surgery for transanal strictureplasty with electrocautery.

\section{Patient characteristics}

In the group of patients with complete follow-up there were 105 women and 184 men with a mean age of 54 years. The higher incidence of stenoses in male was insignificant in statistical analysis $(\mathrm{p}=0.11)$ (Table 1). 211 of 289 patients $(73 \%)$ had no previous interventions, however 5 of the 9 patients (55\%) with stenotic events had previous interventions, in contrast only 73 of 280 patients $(27 \%)$ without stenoses had interventions, which was statistically significant $(\mathrm{p}<0.01)$.

\section{Procedure related characteristics}

All patients underwent SRM (Table 2). As a variable for the details of the surgical technique the question whether one or two string sutures were used, were included into 
Table I: Patient characteristics.

\begin{tabular}{llccc}
\hline Variable & & Stenosis group $(\mathrm{n}=9)$ & No stenosis group $(\mathrm{n}=280)$ & $\mathrm{P}$ value \\
\hline Age & & $55.4 \pm 15.5$ & $54.4 \pm 12.7$ & 0.55 \\
Gender & Male & $8(88.9 \%)$ & $176(62.9 \%)$ & 0.11 \\
\multirow{3}{*}{ Prior treatment } & Female & $1(11.1 \%)$ & $104(37.1 \%)$ & $<07(73.9 \%)$ \\
& None & $4(44.4 \%)$ & $73(26.1 \%)$ & $<0.01$ \\
\hline
\end{tabular}

Table 2: Surgery-related details.

\begin{tabular}{llccc}
\hline Variable & & Stenosis group $(\mathrm{n}=9)$ & No stenosis group $(\mathrm{n}=280)$ & $\mathrm{P}$ value \\
\hline Pursestring suture & 1 & $6(66.7 \%)$ & $96(34.3 \%)$ & \\
technique & 2 & $3(33.3 \%)$ & $184(65.7 \%)$ & 0.25 \\
Histology & Squamous cells & 0 & $22(7.9 \%)$ & $97(34.6 \%)$ \\
\\
Revision & Smouth muscle & $5(55.6 \%)$ & $251(89.6 \%)$ & 0.69 \\
& None & $9(100 \%)$ & $29(10.4 \%)$ & 0.79 \\
Severe pain & One or more & 0 & $5(1.8 \%)$ & $<0.01$ \\
\hline
\end{tabular}

the analysis. Two string sutures were used less often in the stenosis-group but no significance was shown ( $\mathrm{p}=0.25)$. The histological examination of the resected mucosa specimen revealed evidence of squamous skin in 22 specimens. Although this difference reached no significant level, none of the specimens in patients in the stenosisgroup showed squamous cell skin in the histology ( $\mathrm{p}=$ $0.69)$. For different reasons a second operative procedure was carried out in 29 patients $(10 \%)$, none of these patients had a rectal stricture $(\mathrm{p}=0.79)$. In contrast, it was remarkable that 2 of the 9 patients (22\%) from the stenosis-group had severe postoperative pain but only 5 of 280 patients $(2 \%)$ without stenosis experienced severe pain. This difference was statistically significant $(\mathrm{p}<0.01)$.

\section{Discussion}

Rectal stricture is a rare but one of the most disabling complications of anorectal surgery [5-7]. Although strictures of the anorectal junction are known as a result of all kinds of anal operations this specific complication became a focus of interest after introduction of SRM [8]. Accordingly, some basic questions concerning stenotic events following SRM need to be discussed. First is the question whether the stricture can be regarded as rectal stenosis or whether the stenosis is more likely located in the anal canal? According to the classification for postsurgical stenosis, which was published by Milsom et al., the stenoses would be described as high anal stenosis [6]. From our understanding stenoses caused by SRM are presumably rectal stenoses, since the causing event was a resection of rectal mucosa. However, according to technical failure of the procedure, the stapled ring might be placed too deep in the rectum. Thus, although being theoretically regarded as rectal stenosis, the complication might appear as anal stenosis. Secondly, the designation of stenosis is not well defined, while some used an approximate description of the term, Burke defined rectal stenosis as inability to pass a $19 \mathrm{~mm}$ sigmoidoscope effortlessly through a rectal anastomosis $[9,10]$. In this study stenosis was defined as a stricture, which caused difficulty to be passed by a finger. More importantly is probably a definition of the stenosis according to its symptoms. In this respect it was remarkable that in this study only one of nine patients had obstructed defecation. The data presented here give evidence that, according to symptoms, early stenosis of the anal canal or the rectum is not a considerable problem in hemorrhoid surgery using the PPH device.

Since it has been known for years, that intestinal stenosis is a function of time we evaluated the incidence of rectal stenosis by actuarial Kaplan-Meier statistics [11]. The crude incidence of stenosis following SRM is $3.1 \%$ in the presented study, which is comparable to the stenosis-rate published by other authors. A few studies reported no stenotic events after SRM [1,12-18], however the stenosis rate following stapled mucosectomy generally ranges from $0.8-5.0 \%$ [9,19-23] (Table 3). The calculated actuarial one-year stenosis rate is $6 \%$, which is higher than the above-mentioned published stenosis-rates.

Anorectal stenosis is not a specific problem of SRM but a considerable problem after all anal interventions [5]. In 
Table 3: Published data on stenosis after SRM.

\begin{tabular}{lcccc}
\hline Author & Year & Patients & Follow-up (Months) & Stenosis n (\%) \\
\hline Beattie and Loudon [13] & 2001 & 50 & 6 & 0 \\
Boccasanta et al. [19] & 2001 & 40 & 20 & $2(5 \%)$ \\
Correa-Rovelo et al. [9] & 2002 & 42 & 32 & $1(2.4 \%)$ \\
Fantin et al. [I] & 2002 & 16 & 3 & 0 \\
Hetzer et al. [14] & 2002 & 20 & 12 & 0 \\
Ho et al. [20] & 2000 & 57 & 7 & $2(3.5 \%)$ \\
Khalil et al. [15] & 2000 & 20 & 6 & 0 \\
Kirsch et al. [21] & 2001 & 150 & 6 & $3(2 \%)$ \\
Mehigan et al. [16] & 2000 & 20 & 4 & 0 \\
Pavlidis et al. [17] & 2002 & 40 & 12 & 0 \\
Ravo et al. [22] & 2002 & 1107 & n.s. & $9(0,8 \%)$ \\
Rowsell et al. [12] & 2000 & 14 & 22 & 0 \\
Shalaby and Desoky [23] & 2001 & 100 & 12 & $2(2 \%)$ \\
Singer et al. [18] & 2002 & 68 & n.s. & 0 \\
\hline
\end{tabular}

direct comparison in prospective randomized trials there was not a significant difference in stenosis rate between conventional hemorrhoidectomy and SRM $[19,24]$. Nevertheless, the most substantial rate of stenoses was observed following conventional hemorrhoidectomy and probably the highest stenosis rate was described after Whitehead hemorrhoidectomy [5,6,9,21,23].

One potential mechanism that might cause a stenosis following SRM is ring dehiscence followed by submucous inflammation. Another theoretical cause is that the stapled ring is placed too deep in the anal canal and that the squamous skin cell reacts by scaring and shrinking. In this study no events of severe postsurgical infection were observed, thus no conclusion about inflammatory events and rectal stenosis can be drawn from these data. One major aspect of the potential risk of developing a stenosis is the distance to the anal verge. Burke et al. reported of two groups of 24 patients each undergoing prior resection and stapled anastomosis for rectal carcinoma. Three patients developed stenoses in the group of coloanal anastomoses, whereas only one patient experienced a stenosis in the colorectal anastomosis group [10]. In our series the effect of stapling anal skin as a cause for anal stenosis could not be verified. In 22 patients ( $8 \%$ ) squamous cells were observed in the stapled specimen. However, in the stenotic group none of the histologic samples showed squamous cells. Brisanda considered a full thickness excision of the rectal wall another potential cause for stenosis after SRM [25]. According to full thickness excision of the wall, our data provide no conclusive evidence that this point directly caused strictures. The predictive factors presented in this study are previous interventions and severe postsurgical pain. The interpretation of these findings is complex. One potential explanation would be that, although not shown in the histology, the staples ring was too deep in the anal canal, which causes severe pain. The higher rate of prior treatments in the stenosis group, as a potential cause of stenosis, is basically unexplained. Probably, there is already scaring tissue in the high anal canal that increases the stenosis rate.

So the essential question should be addressed, what to do with anal canal stenosis following SRM? The first therapeutic approach is to treat conservatively using a dilatation device $[7,8,11]$. This was also the most commonly used treatment in our study. In eight of the nine patients, this procedure was sufficient to enlarge the stenosis. The observation that dilatation is successful in majority of cases, especially in short strictures, is in good agreement with other publications $[6,7,22]$. However, a small proportion will not profit from dilatation, which was the case in one of nine described stenosis in this series. Although, there is also the potential option to treat a patient using medication, for these cases with persisting scaring stricture surgery seems the only alternative $[9,11]$. A large variety of surgical approaches are available for persisting anorectal stenosis. One of the theoretical approaches is to improve the situation using the mucosal advancement flap [26]. Some authors recommended the so-called Y-V anoplasty or the so-called Diamont-flap $[5,6,27,28]$. Other surgical options are the so-called House-flap or the Island-flap $[29,30]$. Nevertheless, it remains questionable whether the above-mentioned techniques are suitable for rectal stenosis as well as for strictures of the anal canal. In the one case with persisting stenosis after dilatation we decided to carve the scaring ring longitudinaly. So far the patient developed no stenotic recurrence and defecation was normalized. Another option for the treatment of intestinal strictures is the endoscopic transanal stricturoplasty using a linear cutter device, however there are no reports published where these techniques became neces- 
sary for SRM related stenosis [31-33]. Colostomy is necessary in a minority of cases and fortunately there are no papers published on this procedure associated with SRM [11].

\section{Conclusion}

Although, conclusion drawn from a retrospective analysis are of limited value, especially when the follow-up is incomplete, the data presented here provide evidence that symptomatic rectal stenosis is an uncommon event after SRM. Early stenosis will occur within the first three months after surgery. However, due to a short follow-up of less than a year, no conclusion according late stenotic events can be made. The majority of the stenoses are without clinical relevance. Only one of nine patients had to undergo surgery for a relevant stenosis. The predictive factors for stenosis in the patient-characteristics are previous interventions for hemorrhoids and severe postoperative pain. Patients, who wish to undergo the SRM method must know that there are not only striking advantages from the SRM method but also potential serious complications [34].

\section{List of abbreviations}

SRM - stapled rectal mucosectomy

\section{Competing interests}

None declared.

\section{Authors' contributions}

SP was responsible for the statistical analysis and the draft of the manuscript, GH created the study and initiated the prospective analysis and the follow-up, DS participated in the data collection, AS participated in the preparation of the manuscript, KL provided the scientific and logistic background.

\section{References}

I. Fantin AC, Hetzer FH, Christ AD, Fried M, Schwizer W: Influence of stapler haemorrhoidectomy on anorectal function and on patients' acceptance. Swiss Med Wkly 2002, I32:38-42.

2. Sutherland LM, Burchard AK, Matsuda K, Sweeney JL, Bokey EL, Childs PA, Roberts AK, Waxman BP, Maddern Gl: A systematic review of stapled hemorrhoidectomy. Arch Surg 2002, 137: 1395-406; discussion 1407.

3. Maw A, Eu KW, Seow-Choen F: Retroperitoneal sepsis complicating stapled hemorrhoidectomy: report of a case and review of the literature. Dis Colon Rectum 2002, 45:826-828.

4. Lehur PA, Gravie JF, Meurette G: Circular stapled anopexy for hemorrhoidal disease: results. Colorectal Disease 200I, 3:374-379.

5. Maria G, Brisinda G, Civello IM: Anoplasty for the treatment of anal stenosis. Am J Surg 1998, I75: I58-160.

6. Milsom JW, Mazier WP: Classification and management of postsurgical anal stenosis. Surg Gynecol Obstet 1986, 163:60-64.

7. Garcea G, Sutton CD, Lloyd TD, Jameson J, Scott A, Kelly MJ: Management of benign rectal strictures. Dis Colon Rectum 2003, 46: $1451-1460$

8. Pescatori M: Management of post-anopexy rectal stricture. Tech Coloproctol 2002, 6:125-126.

9. Correa-Rovelo JM, Tellez O, Obregon L, Miranda-Gomez A, Moran S: Stapled rectal mucosectomy vs. closed hemorrhoidec- tomy: a randomized, clinical trial. Dis Colon Rectum 2002 , 45: I 367-74; discussion I374-5..

10. Burke ER, Welvaart K: Complications of stapled anastomoses in anterior resection for rectal carcinoma: colorectal anastomosis versus coloanal anastomosis. J Surg Oncol 1990, 45: $180-183$.

II. Luchtefeld MA, Milsom JW, Senagore A, Surrell JA, Mazier WP: Colorectal anastomotic stenosis. Results of a survey of the ASCRS membership. Dis Colon Rectum 1989, 32:733-736.

12. Rowsell $M$, Bello $M$, Hemingway DM: Pain after stapled haemorrhoidectomy. Lancet 2000, 356:2188; author reply 2190.

13. Beattie GC, Loudon MA: Follow-up confirms sustained benefit of circumferential stapled anoplasty in the management of prolapsing haemorrhoids. Br J Surg 200I, 88:850-852.

14. Hetzer FH, Demartines N, Handschin AE, Clavien PA: Stapled vs excision hemorrhoidectomy: long-term results of a prospective randomized trial. Arch Surg 2002, I 37:337-340.

15. Khalil KH, O'Bichere A, Sellu D: Randomized clinical trial of sutured versus stapled closed haemorrhoidectomy. $\mathrm{Br} J$ Surg 2000, 87: I352-I355.

16. Mehigan BJ, Monson JR, Hartley JE: Stapling procedure for haemorrhoids versus Milligan-Morgan haemorrhoidectomy: randomised controlled trial. Lancet 2000, 355:782-785.

17. Pavlidis T, Papaziogas B, Souparis A, Patsas A, Koutelidakis I, Papaziogas T: Modern stapled Longo procedure vs. conventional Milligan-Morgan hemorrhoidectomy: a randomized controlled trial. Int J Colorectal Dis 2002, I 7:50-53.

18. Singer MA, Cintron JR, Fleshman JW, Chaudhry V, Birnbaum EH, Read TE, Spitz JS, Abcarian H: Early experience with stapled hemorrhoidectomy in the United States. Dis Colon Rectum 2002, 45:360-7; discussion 367-9..

19. Boccasanta P, Capretti PG, Venturi M, Cioffi U, De Simone M, Salamina G, Contessini-Avesani E, Peracchia A: Randomised controlled trial between stapled circumferential mucosectomy and conventional circular hemorrhoidectomy in advanced hemorrhoids with external mucosal prolapse. Am J Surg 200I, 182:64-68.

20. Ho YH, Cheong WK, Tsang C, Ho J, Eu KW, Tang CL, Seow-Choen F: Stapled hemorrhoidectomy--cost and effectiveness. Randomized, controlled trial including incontinence scoring, anorectal manometry, and endoanal ultrasound assessments at up to three months. Dis Colon Rectum 2000, 43:1666-1675.

21. Kirsch J], Staude G, Herold A: [The Longo and Milligan-Morgan hemorrhoidectomy. A prospective comparative study of $\mathbf{3 0 0}$ patients]. Chirurg 200I, 72:180-185.

22. Ravo B, Amato A, Bianco V, Boccasanta P, Bottini C, Carriero A, Milito G, Dodi G, Mascagni D, Orsini S, Pietroletti R, Ripetti V, Tagariello GB: Complications after stapled hemorrhoidectomy: can they be prevented? Tech Coloproctol 2002, 6:83-88.

23. Shalaby R, Desoky A: Randomized clinical trial of stapled versus Milligan-Morgan haemorrhoidectomy. Br J Surg 200I, 88: $1049-1053$.

24. Wilson MS, Pope V, Doran HE, Fearn SJ, Brough WA: Objective comparison of stapled anopexy and open hemorrhoidectomy: a randomized, controlled trial. Dis Colon Rectum 2002. 45: | 437-1444.

25. Brisinda G: How to treat haemorrhoids. Prevention is best; haemorrhoidectomy needs skilled operators. Bmj 2000 32I:582-583.

26. Khubchandani IT: Mucosal advancement anoplasty. Dis Colon Rectum 1985, 28:194-196.

27. Angelchik PD, Harms BA, Starling JR: Repair of anal stricture and mucosal ectropion with $\mathbf{Y}-\mathbf{V}$ or pedicle flap anoplasty. Am J Surg 1993, 166:55-59.

28. Caplin DA, Kodner IJ: Repair of anal stricture and mucosal ectropion by simple flap procedures. Dis Colon Rectum 1986 , 29:92-94.

29. Sentovich SM, Falk PM, Christensen MA, Thorson AG, Blatchford GJ, Pitsch RM: Operative results of House advancement anoplasty. Br J Surg 1996, 83: I 242- I244.

30. Pearl RK, Hooks V. H., 3rd, Abcarian H, Orsay CP, Nelson RL: Island flap anoplasty for the treatment of anal stricture and mucosal ectropion. Dis Colon Rectum 1990, 33:58I-583.

31. Anvari M: Endoscopic transanal rectal stricturoplasty. Surg Laparosc Endosc 1998, 8:193-196. 
32. Schlegel RD, Dehni N, Parc R, Caplin S, Tiret E: Results of reoperations in colorectal anastomotic strictures. Dis Colon Rectum 200I, 44: I 464-I 468.

33. Hunt TM, Kelly MJ: Endoscopic transanal resection (ETAR) of colorectal strictures in stapled anastomoses. Ann R Coll Surg Engl 1994, 76: I21-122.

34. Pescatori M: stapled hemorrhoidectomy: a word of caution. Int J Colorectal Dis 2002, 17:362-363.

\section{Pre-publication history}

The pre-publication history for this paper can be accessed here:

http://www.biomedcentral.com/1471-2482/4/6/prepub

Publish with Biomed Central and every scientist can read your work free of charge

"BioMed Central will be the most significant development for disseminating the results of biomedical research in our lifetime. " Sir Paul Nurse, Cancer Research UK

Your research papers will be:

- available free of charge to the entire biomedical community

- peer reviewed and published immediately upon acceptance

- cited in PubMed and archived on PubMed Central

- yours - you keep the copyright 